\title{
Brain responses to musical feature changes in adolescent cochlear implant users
}

\author{
Bjørn Petersen ${ }^{1,2}$ *, Ethan Weed ${ }^{1,3}$, Pascale Sandmann ${ }^{4}$, Elvira Brattico ${ }^{5,6}$, Mads Hansen $^{1,7}$, \\ Stine Derdau Sørensen ${ }^{3}$ and Peter Vuust ${ }^{1,2}$ \\ ${ }^{1}$ Center for Functionally Integrative Neuroscience, Aarhus University Hospital, Aarhus, Denmark \\ ${ }^{2}$ Royal Academy of Music, Aarhus, Denmark \\ ${ }^{3}$ Department of Aesthetics and Communication - Linguistics, Aarhus University, Aarhus, Denmark \\ ${ }^{4}$ Central Auditory Diagnostics Lab, Department of Neurology, Cluster of Excellence "Hearing4all," Hannover Medical School, Hannover, Germany \\ ${ }^{5}$ Brain and Mind Laboratory, Department of Biomedical Engineering and Computational Science, Aalto University, Aalto, Finland \\ ${ }^{6}$ Cognitive Brain Research Unit, Institute of Behavioral Sciences, University of Helsinki, Helsinki, Finland \\ ${ }^{7}$ Department of Psychology and Behavioural Sciences, Aarhus University, Aarhus, Denmark
}

Edited by:

Teppo Särkämö, University of

Helsinki, Finland

\section{Reviewed by:}

Hidenao Fukuyama, Kyoto University,

Japan

Daniele Schön, CNRS, France

*Correspondence:

Bjørn Petersen, Center for

Functionally Integrative Neuroscience

(CFIN), Norrebrogade 44, Building

10G, 5th Floor, Aarhus C 8000,

Denmark

e-mail:bjorn@pet.auh.dk
Cochlear implants (Cls) are primarily designed to assist deaf individuals in perception of speech, although possibilities for music fruition have also been documented. Previous studies have indicated the existence of neural correlates of residual music skills in postlingually deaf adults and children. However, little is known about the behavioral and neural correlates of music perception in the new generation of prelingually deaf adolescents who grew up with Cls. With electroencephalography (EEG), we recorded the mismatch negativity (MMN) of the auditory event-related potential to changes in musical features in adolescent $\mathrm{Cl}$ users and in normal-hearing $(\mathrm{NH})$ age mates. EEG recordings and behavioral testing were carried out before (T1) and after (T2) a 2-week music training program for the $\mathrm{Cl}$ users and in two sessions equally separated in time for $\mathrm{NH}$ controls. We found significant MMNs in adolescent $\mathrm{Cl}$ users for deviations in timbre, intensity, and rhythm, indicating residual neural prerequisites for musical feature processing. By contrast, only one of the two pitch deviants elicited an $\mathrm{MMN}$ in $\mathrm{Cl}$ users. This pitch discrimination deficit was supported by behavioral measures, in which $\mathrm{Cl}$ users scored significantly below the $\mathrm{NH}$ level. Overall, MMN amplitudes were significantly smaller in $\mathrm{Cl}$ users than in $\mathrm{NH}$ controls, suggesting poorer music discrimination ability. Despite compliance from the $\mathrm{Cl}$ participants, we found no effect of the music training, likely resulting from the brevity of the program. This is the first study showing significant brain responses to musical feature changes in prelingually deaf adolescent $\mathrm{Cl}$ users and their associations with behavioral measures, implying neural predispositions for at least some aspects of music processing. Future studies should test any beneficial effects of a longer lasting music intervention in adolescent $\mathrm{Cl}$ users.

Keywords: cochlear implants, adolescents, music perception, mismatch negativity, music training, rehabilitation, auditory cortex

\section{INTRODUCTION}

The cochlear implant $(\mathrm{CI})$ is a neural prosthesis that provides profoundly deaf individuals with the opportunity to gain or regain the sense of hearing. The implant transforms acoustic signals into electric impulses, which are delivered to an electrode array implanted within the cochlea. The electrodes stimulate intact auditory nerve fibers at different places in the cochlea, thus mimicking the tonotopic organization of the healthy cochlea (Loizou, 1999; McDermott, 2004). The clinical impact of the device is extraordinary, allowing postlingually deafened adults to restore speech comprehension and children to acquire language. Adults with prelingual hearing loss may achieve some auditory alerting functions, but rarely speech comprehension (e.g., Petersen et al., 2013a).

The majority of postlingually deafened adult CI users achieve good speech perception in quiet but their perception of music remains poor. Several studies show that due to low spectral resolution and compromised temporal finestructure information, discrimination of pitch, melody, timbre, and emotional prosody is significantly poorer in CI users than in normal-hearing (NH) listeners (Leal et al., 2003; Kong et al., 2004; Gfeller et al., 2005, 2007; Olszewski et al., 2005; Cooper et al., 2008; Timm et al., 2012; Agrawal, 2013). Nevertheless, there are examples of CI users who seem to enjoy music after repeated listening (Gfeller and Lansing, 1991; Gfeller et al., 2005) and some studies show significantly improved music discrimination after computer-assisted training (Gfeller et al., 2000a, 2002b; Galvin et al., 2007) and after long-term one-to-one musical ear training (Petersen et al., 2012). These findings suggest that CI users typically do not extract all of the (degraded) information available from the CI signal (Moore and Shannon, 2009) and that targeted auditory training maximizes the benefits of the implant (Fu and Galvin, 2008). Beyond the potential beneficial effects on music enjoyment and social functioning, improved music perception may have positive implications for the quality of life in CI users (Gfeller et al., 2000b; Drennan and Rubinstein, 2008; Lassaletta et al., 2008; Wright and Uchanski, 2012; Petersen et al., 2013b). Furthermore, 
musical training might transfer to non-musical domains and may have beneficial effects on speech perception in noisy surroundings (Qin and Oxenham, 2003; Parbery-Clark et al., 2009; Won et al., 2010) and on the ability to recognize gender and identity of the speaker (Vongphoe and Zeng, 2005).

In this context, the new generation of prelingually deaf children, who have grown up with the assistance of CIs and who have now become teenagers, is of particular interest. While postlingually deafened CI users rely on auditory development formed by previous hearing experience in processing auditory information from the CI, most current adolescent CI users are congenitally deaf and have only heard sound through their implant. In addition, most young CI users were not diagnosed until they were 2-3 years old and subsequently received their CI after the first 3-5 years of life, that is, beyond the sensitive period for cochlear implantation (Sharma et al., 2002b; Kral and Sharma, 2012).

Initially, cochlear implantation was offered primarily to adults, whereas children were included in CI-programs at a later stage (in Denmark since 1993) and only in moderate numbers. Thus, information about this new population of CI users, their educational placement, and linguistic development has so far been sparse. A recent Danish survey indicate that a majority of young CI users communicate by auditory methods (36\%) or auditory methods supported by lip-reading (47\%), whereas as few as $5 \%$ depend on sign language. Background noise, small talk, slang language, joking, irony, and phone conversation with strangers, however, are reported to represent very challenging daily communicative situations (Rosenmeier and Møller Hansen, 2013). While the findings are an encouraging indication of the overall success of pediatric cochlear implantation (Bosco, 2012), these difficulties highlight the need for continuing specialist teaching throughout adolescence (Archbold et al., 2008; Geers et al., 2008; Harris and Terlektsi, 2011). Adolescence is an age when self-identify is forming and social relations, including music listening and preferences, are particularly important in the life of a teenager (North et al., 2000). Considering that well-functioning communicational skills are crucial for adolescent CI users' well-being, self-esteem, social functioning, and educational prospects (Hansen, 2012), it is pivotal to understand the neural substrates of their speech and music processing to further develop their hearing and speech skills. Nevertheless, while a few behavioral studies have been conducted on adolescent CI users who were prelingually deaf (Geers et al., 2008; Gfeller et al., 2012), no information is currently at hand concerning the neural correlates of musical sound perception and musical training in adolescent CI users.

Auditory processing in CI users can be studied by recording auditory event-related potentials (ERP) using electroencephalography (EEG) (Sharma et al., 2002a; Pantev et al., 2006; Debener, 2008; Sandmann et al., 2009, 2014). One component of the auditory ERP is the mismatch negativity $(\mathrm{MMN})$, which is related to change in different sound features such as pitch, timbre, harmony, intensity, and rhythm (Näätänen et al., 2001, 2007). In contrast to subjective behavioral measures, the MMN represents a reliable and objective marker for CI users' ability to accurately discriminate auditory stimuli (Sandmann et al., 2010; Torppa et al., 2012) typically elicited pre-attentively, in the absence of participants' attention toward the stimuli. MMN latency and amplitude reflect the magnitude of perceptual difference between deviant and standard stimulus and are associated with auditory behavioral measures (Näätänen et al., 2007).

A few MMN studies have investigated auditory brain processing of music in children and adult CI users. For instance, Koelsch (2004) reported timbre-evoked MMN responses with reduced amplitudes in postlingually deaf CI users compared to NH control participants. In a study with postlingually deaf adult CI recipients, Sandmann et al. (2010) reported smaller MMN amplitudes for frequency and intensity deviations in CI users compared to $\mathrm{NH}$ controls, and found no robust MMNs to duration deviants in neither of the two groups. In a study with early-implanted CI children (mean age 6 years, 10 months), Torppa et al. (2012) reported comparable magnitudes and latencies of $\mathrm{MMN}$ responses to three and seven semitone pitch changes in $\mathrm{CI}$ and $\mathrm{NH}$ children, and significant MMNs to timbre only for a change from piano to cymbal in both groups. Interestingly, Torppa et al. (2014) in a recent longitudinal study found enhanced development of P3a (attention toward salient sounds) to pitch, timbre, and rhythm changes in CI children who sang regularly, not observed in CI children who did not sing.

Using a newly developed musical multi-feature paradigm, Timm et al. (2014) found distinct MMN responses to pitch, timbre, and intensity, but not to rhythm in postlingually deafened adults with CI. In the present study, we wished to study for the first time the neural prerequisites for music perception, and particularly for musical feature change discrimination, in prelingually deaf adolescent CI users by applying the same paradigm as in Timm et al. (2014). We hypothesized that if any MMN would be found to musical feature changes it would testify the existence of neural predispositions for musical feature processing even in prelingually deaf CI users who were not exposed to any musical (or speech) sounds during the critical period of development. Additionally, we wanted to test whether these adolescent CI users would have any beneficial effect even from a short but intensive music training program. For this purpose, the CI users were measured before and after a musical intervention lasting 2 weeks $(20 \mathrm{~h})$, consisting of singing, rhythm, and ear training as well as computer-assisted musical quizzes. We predicted that adolescent CI users would show MMNs, which would differ from those of $\mathrm{NH}$ peers, particularly with smaller MMN amplitudes and longer latencies to changes in the acoustic properties of musical sounds, reflecting their impaired musical skills as in behavioral tests. Moreover, we expected to observe a relation between the behavioral effects of music training and the MMN amplitude and latency.

\section{MATERIALS AND METHODS PARTICIPANTS}

The participants were all recruited from Frijsenborg Efterskole (post-school) in the city of Hammel, Denmark. Frijsenborg Efterskole has specialized in teaching hearing-aid (HA) and CI users and employs teachers who are specialized in teaching hearingimpaired pupils and provides modern aids that promote teaching and communication, such as multi-frequency FM equipment. The hearing-impaired pupils make up $25 \%$ of the students. The remaining part of the pupils is typical $\mathrm{NH}$ age mates. 
The participants were recruited through a procedure in which they received oral as well as written information about the project. Since all participants, except one, were below the age of 18 years, their parents received written information also and were required to give informed consent on behalf of their children. The participants received no monetary compensation for their time. The study was conducted in accordance with the Helsinki declaration and approved by the Research Ethics Committee of the Central Denmark Region and is part of a broader study.

All of the school's 12 adolescent CI users signed up for the study, but, due to illness, one had to withdraw from the project. The remaining $11 \mathrm{CI}$ users $\left(6\right.$ girls, 5 boys, $M_{\text {age }}=17.0$ years, age range: $15.6-18.8$ years), committed themselves to 2 weeks of music training and two sessions of EEG recording and behavioral tests one before and one after the training period. In the following, T1 and $\mathrm{T} 2$ refer to EEG recordings and behavioral tests administered before and after the 2-weeks intervention period, respectively.

The CI participants had a severe-profound/profound congenital or prelingual hearing loss and had received their CI at different points of time in childhood or adolescence $\left(M_{\text {age }}\right.$ at implant $=7.5$ years; range: $2.2-14.9$ years) between 1997 and 2011, with the majority of participants implanted between 2001 and 2003. The mean implant experience was 9.5 years (range: 1.8-15.2). Nine CI users had bilateral implants, in all cases received sequentially $\left(M_{\text {age }}\right.$ at implant $2=12.0$ years; range: $10.5-$ 16.6 years; mean experience w. CI $2=5.2$; range: $0.1-6.2$ ) and two CI participants had unilateral implants combined with a contra-lateral HA. All of the participants used the Nucleus Freedom device from Cochlear Corporation. All CI participants had $\mathrm{NH}$, monolingual Danish-speaking parents. The clinical and demographic data of the 11 CI participants are shown in Table 1.
The NH reference group consisted of 10 participants (2 girls, 8 boys; $M_{\text {age }}=16.2$ years, age range: $15.3-17.0$ years), who committed themselves to two sessions of EEG recording and tests with a 14-day-interval. The NH reference group followed their normal school schedule during the project and received no musical training. By testing the $\mathrm{NH}$ participants twice, we acquired measurements that could be used for direct comparisons with the CI group before and after training.

\section{Musical background}

To account for past and recent musical training and experience, the participants filled out a questionnaire concerning their musical background. All NH participants had attended music classes in primary school, as had all CI participants except one. Four CI participants had sung in a choir, which was only the case for two in the NH group. Two in each group stated that they had played in a band at some point. Four CI users had received musical instrument lessons, which was also the case for five NH participants, typically guitar, bass, or drums and in all cases for a short period of time. Based on this information, we judged the musical background in the two groups to be comparable.

\section{THE MUSIC TRAINING PROGRAM}

The music training program aimed at strengthening the participants' perception of the fundamental resources in music: pitch, rhythm, and timbre in a combination of active music-making sessions and computer-based listening exercises. The active training part totaled $20 \mathrm{~h}$, scheduled over 6 days, and distributed over 2 weeks. The activities were formed by three elements: rhythm training, singing, and ear training and were led by two masters' students from Royal Academy of Music, Aarhus and the first author,

Table 1 | Clinical and demographic data of the 11 participants in the $\mathrm{Cl}$ group.

\begin{tabular}{|c|c|c|c|c|c|c|c|c|c|}
\hline $\begin{array}{l}\text { Participant } \\
\text { (gender) }\end{array}$ & $\begin{array}{l}\text { Age at project } \\
\text { start (years) }\end{array}$ & $\begin{array}{l}\text { Etiology of } \\
\text { deafness }\end{array}$ & $\begin{array}{l}\text { Side of } \\
\text { first } \\
\text { implant }\end{array}$ & $\begin{array}{l}\text { Contra- } \\
\text { lateral } \\
\text { use of HA }\end{array}$ & $\begin{array}{l}\text { Cl } 1 \\
\text { experience } \\
\text { (years) }\end{array}$ & $\begin{array}{l}\mathrm{Cl} 2 \\
\text { experience } \\
\text { (years) }\end{array}$ & $\begin{array}{l}\text { Use of } \\
\text { sign- } \\
\text { language }^{e}\end{array}$ & $\begin{array}{l}\text { Use of } \\
\text { lip- } \\
\text { readinge }^{e}\end{array}$ & $\begin{array}{l}\text { Ability to } \\
\text { speak on } \\
\text { the phone }\end{array}$ \\
\hline \multicolumn{10}{|l|}{ CI GROUP } \\
\hline $\mathrm{Cl} 1(\mathrm{~F})$ & 17.8 & ${ }^{\mathrm{a} C o n g . ~ n o n-s p e c . ~}$ & $\mathrm{~L}$ & & 10.1 & 5.9 & 4 & 5 & $X$ \\
\hline $\mathrm{Cl} 2(\mathrm{~F})$ & 15.5 & ${ }^{\mathrm{b}}$ Pendred & $\mathrm{R}$ & $x$ & 4.1 & & 1 & 2 & $x$ \\
\hline $\mathrm{Cl} 3(\mathrm{~F})$ & 16.5 & Unknown & $\mathrm{L}$ & & 11.1 & 5.6 & 5 & 5 & $x$ \\
\hline $\mathrm{Cl} 4(\mathrm{M})$ & 16.6 & ${ }^{\mathrm{c}} \mathrm{CMV}$ & $\mathrm{L}$ & $x$ & 3.0 & & 1 & 2 & $x$ \\
\hline $\mathrm{Cl} 5(\mathrm{M})$ & 18.8 & Cong. non-spec. & $\mathrm{R}$ & & 9.9 & 5.7 & 4 & 2 & \\
\hline $\mathrm{Cl} 6(\mathrm{M})$ & 17.3 & Cong. non-spec. & $\mathrm{R}$ & & 11.4 & 6.1 & 3 & 4 & $x$ \\
\hline $\mathrm{Cl} 7(\mathrm{~F})$ & 16.2 & Pendred & $\mathrm{R}$ & & 11.8 & 5.0 & 3 & 3 & \\
\hline $\mathrm{Cl} 8(\mathrm{M})$ & 16.6 & Meningitis & $\mathrm{L}$ & & 13.4 & 6.0 & 3 & 2 & $x$ \\
\hline $\mathrm{Cl} 9(\mathrm{~F})$ & 17.4 & dHer. non-spec. & $\mathrm{R}$ & & 15.7 & 6.2 & 4 & 3 & $x$ \\
\hline $\mathrm{Cl} 10$ (M) & 16.7 & CMV & $\mathrm{L}$ & & 1.8 & 0.1 & 3 & 5 & $x$ \\
\hline $\mathrm{Cl} 11(\mathrm{~F})$ & 17.6 & Cong. non-spec. & $\mathrm{L}$ & & 12.0 & 6.1 & 5 & 5 & $x$ \\
\hline Mean & 17.0 & & & & 9.5 & 5.2 & 3.3 & 3.5 & \\
\hline Range & (15.6-18.8) & & & & $(1.8-15.2)$ & $(0.1-6.2)$ & & & \\
\hline
\end{tabular}

${ }^{a}$ Non-specified congenital hearing loss.

${ }^{b}$ Pendred Syndrome.

${ }^{c}$ Cytomegalovirus.

${ }^{d}$ Non-specified hereditary hearing loss.

"Indicated on a scale where 5 is "everyday" and 1 is "never." 
who has previous experience with music training of adult and pediatric CI users (Petersen et al., 2011, 2012). Training took place in the school's two music classrooms, which were acoustically well suited and well equipped.

\section{Rhythm training}

The intention of the rhythm training sessions was to establish a fundamental sense of meter, period, and subdivision in a motivating and physically engaging manner. The sessions involved recurrent exercises including coordination of foot stomping, clapping, and "rapping". All exercises were in 4/4-time in tempos between 80 and 110 BPM. The exercises were performed in a circle, standing up.

\section{Singing}

The purpose of the singing training was to establish a sense of basic musical attributes such as high/low, up/down, far/close, and melodic direction. The singing training involved technical instructions about breath control/belly support and exercises, such as glissando (up/down), and imitation of short phrases with focus on long/short, strong/weak, and open/closed vowel sounds in different vocal registers.

\section{Ear training}

The ear training part aimed at improving the participants' general music perception skills, particularly timbre, pitch, and melody in a standard classroom setting. The group was introduced to different instruments in live demonstrations. For perception of pitch and melody, the participants were required to identify the direction of two notes (up, down) or three notes (up-down, downup) or recognize familiar melodies presented on piano or other instruments.

\section{Musical quizzes}

To support the ear training sessions, several computer applications, presented as musical quizzes, were developed and made available through download from a website. The quizzes were adapted and expanded versions of applications described in Petersen et al. (2012), aiming to train discrimination of melodic contour, timbre, melody, and rhythm. All quizzes were designed with a familiarization part followed by a number of trials, which required the user to match presented sounds with corresponding icons on the screen. The participants were asked to train everyday for 10-20 min during the 2 -weeks training period.

\section{EEG RECORDING}

\section{Stimuli and procedure}

Electroencephalography was recorded with a musical multifeature MMN paradigm (Vuust et al., 2011), in a version previously adapted for a study with adult CI users (Timm et al., 2014). The musical multi-feature paradigm presents musical standards, pseudorandomly violated by different deviants in the context of musical four-tone patterns. The four-tone patterns consist of major triads arranged in an "Alberti bass" configuration, an accompaniment commonly used in the Western musical culture.

In the adapted configuration, deviant patterns were similar to standards, except that the third tone of the pattern was exchanged with one of six deviants: (1) pitch deviant (Pitch $\left.1_{D 1}\right)$, which was created by raising the standard note by two semitones, (2) pitch deviant (Pitch2 $\mathrm{D} 2$ ), which was created by raising the standard by four semitones, (3) timbre deviant ( $\mathrm{Gui}_{\mathrm{D} 3}$ ), which was created by replacing the standard piano timbre with the sound of an electric guitar, (4) timbre deviant $\left(\mathrm{Sax}_{\mathrm{D} 4}\right)$, which was created by replacing the standard piano timbre with the sound of a saxophone, (5) intensity deviant $\left(\mathrm{Int}_{\mathrm{D} 5}\right)$, which was created by reducing the original intensity by $12 \mathrm{~dB}$, and (6) rhythm deviant (RhyD6), which was created by anticipating the third note by $60 \mathrm{~ms}$. In contrast to the more subtle deviants encompassed in the original multifeature paradigm aimed at musicians and non-musicians (Vuust et al., 2011), the deviants in the present study were enhanced, thus taking the crude sound representation of the CI into consideration. Each tone was in stereo, 44,100 in sample frequency, and $200 \mathrm{~ms}$ in duration, having an inter-stimulus-interval (ISI) of 5 ms. For the Rhy 6 deviant, the note prior to the third note was shortened to $140 \mathrm{~ms}$ and the ISI between third and fourth note extended to $65 \mathrm{~ms}$. The position of the fourth note was preserved, thus leaving the metric pulse uninterrupted. To make the stimuli more musically interesting, we changed the key every sixth measure, allowing for the six different types of deviants to appear in four different keys. The order of the four possible keys (F, G, A, and C) was pseudo-randomized, so that each key appeared six times in the duration of the paradigm. The keys were kept in the middle register of the piano with the bass note between F3 and C4. The stimuli were presented in Presentation software (Neurobehavioral Systems). The paradigm presented a total of 4608 stimuli, making the duration of whole experiment approximately $18 \mathrm{~min}$, including two 1-min-pauses (Figure 1). For more details about the paradigm, see Timm et al. (2014).

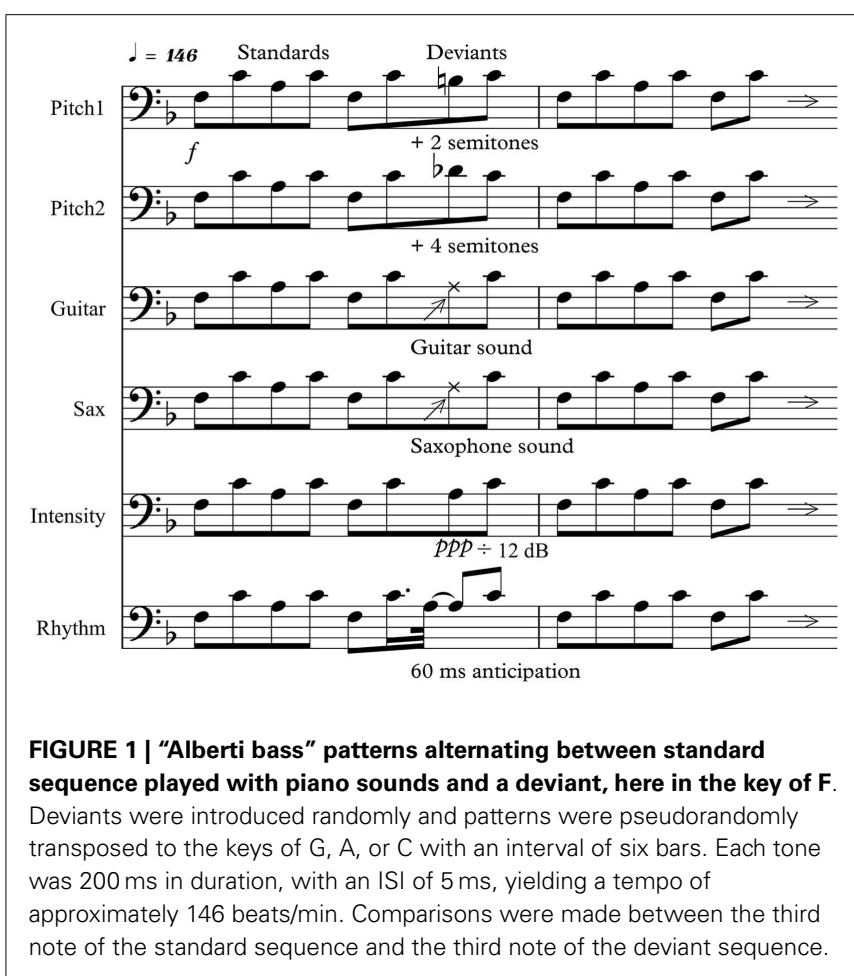




\section{EEG data recording and analysis}

Recording of EEG took place in an acoustically dampened room at Frijsenborg Efterskole. Participants were seated in front of two active loudspeakers (Genelec 8020B; Genelec Oy, Iisalmi, Finland) placed to their left and right side with a $45^{\circ}$ angle, approximately $0.5 \mathrm{~m}$ distance from the participants' ear. Participants were instructed to ignore the auditory stimuli and watch an animated subtitled movie presented without sound.

The stimuli were presented at $65 \mathrm{~dB}$ SPL. CI users used their everyday processor settings during the EEG session. To assure the most comfortable level, participants were exposed to the stimuli briefly before the EEG recording, thus getting an opportunity to adjust their processor settings. To assure comparable conditions for CI participants, bilateral CI users were asked to use only their preferred implant and bimodally aided participants were asked to remove their hearing aid.

Electroencephalography was recorded from $30 \mathrm{Ag} / \mathrm{AgCl}$ electrodes placed according to the International 10-20 system and using a BrainAmp amplifier system (Brainproducts, Gilching, Germany). Two additional electrodes were placed below the left and right eye to record the electrooculogram. For CI users, some channels could not be used because of the location of the CI device. Data were recorded with a sampling rate of $500 \mathrm{~Hz}$ using the position $\mathrm{FCz}$ as reference, and were analog filtered between 0.02 and $250 \mathrm{~Hz}$. Electrode impedances were maintained below $5 \mathrm{k} \Omega$ prior to data acquisition.

Electroencephalography data were analyzed with custom scripts and EEGLAB 12.0.2.4b (Delorme, 2004) running in the MATLAB environment (Mathworks, Natick, MA, USA). The preprocessing was done using a two-step procedure, optimized for artifact correction with independent component analysis (ICA) (e.g., Debener et al., 2010). In the first step, the raw data were offline filtered $(1-40 \mathrm{~Hz})$ and epoched into continuous $2 \mathrm{~s}$ intervals. Intervals containing unique, non-stereotyped artifacts were rejected (threshold: 3 SD). Infomax ICA was computed on the remaining data. In the second step, the resulting ICA weights were applied to the raw data filtered between 0.5 and $30 \mathrm{~Hz}$. Note that the different filter settings for ICA training and ERP analysis was done according to previous recommendations (Debener et al., 2010) and accounted for the otherwise adverse effect of slow amplitude drifts $(<1 \mathrm{~Hz})$ on ICA data decomposition. Independent components representing eye-blinks, horizontal eye movement, and electrocardiographic artifacts were identified semi-automatically and were corrected from all datasets using CORRMAP (Viola et al., 2009). Next, the data were segmented from -100 ms to $400 \mathrm{~ms}$ relative to stimulus onset, and components representing CI artifacts and other non-cerebral activity were identified by visual inspection of various component properties. Independent components representing $\mathrm{CI}$ artifacts were identified by the centroid on the side of the implanted device, and by the time course of component activity (for details on the reduction of CI artifacts by means of ICA, see Gilley, 2006; Debener, 2008; Sandmann et al., 2009). The total number of rejected ICA components was (means and SEM): $8 \pm 0.7$ for the CI users before training, $9 \pm 0.7$ for the CI users after training, $10 \pm 0.7$ for the $\mathrm{NH}$ listeners in the first session, and $9 \pm 0.9$ for the $\mathrm{NH}$ listeners in the second session. The data were then pruned of unique, non-stereotyped artifacts (threshold:
3 standard deviations), and unused channels were interpolated (mean: 2 electrodes; SEM: 0.4; range: 1-3 electrodes) using the EEGLAB function eeg_interp.m, before re-referencing the data to a common average reference. Finally, ERPs were obtained by timedomain averaging, and the pre-stimulus interval from -100 to $0 \mathrm{~ms}$ was used for baseline correction.

\section{MMN quantification}

Difference waveforms were computed for each participant by subtracting the response to the standard stimulus from each of the six deviant stimuli. MMN's were identified with the following procedure. First, a grand-average difference wave was constructed for each deviant by combining the difference waves from the two recording sessions. This was done separately for the $\mathrm{NH}$ and the CI group. Next, a $40 \mathrm{~ms}$ time window was defined, centered on the most negative point at 75-205 $\mathrm{ms}$ in the grand-average difference waves. Finally, the MMN was measured as the peak amplitude within the $40 \mathrm{~ms}$ window at the Fz electrode site for each participant, deviant type, and recording session. To avoid erroneously high or low values, three data points on either side of the peak were included in the peak measurement (14 ms duration in total). MMN latency was measured as the peak amplitude between 75 and $205 \mathrm{~ms}$ at $\mathrm{Fz}$ electrode for each participant, deviant type, and recording session.

\section{BEHAVIORAL MEASUREMENTS Musical multi feature discrimination task}

All participants completed a music discrimination test before and after the intervention period. The purpose was to obtain a behavioral measurement of auditory discrimination accuracy of the six musical deviants also used in the MMN paradigm. The test was designed as a three-alternative forced-choice task (3-AFC), in which the participants were presented with a similar four-tone piano pattern as used in the EEG experiment, restricted, though, to the key of $\mathrm{C}$ major. The pattern was presented thrice in a row, twice in the standard, and once in the deviant condition. The deviant patterns were presented equally often and were repeated 6 times in random order, occurring as either the first, the second, or the third pattern, adding to a total of 36 trials. Participants were instructed to click pictorial representations of the pattern, indicating at which position the deviating pattern had occurred. The scores were converted to percent correct hit rates for the six deviant conditions.

Dantale II test. To measure speech comprehension, we used the Danish speech material Dantale II (Wagener et al., 2003). In the applied configuration, this sentence test adapts to the respondent's performance by increasing or decreasing the volume of the speech, holding the background noise at a constant level. The result of the test is given as the speech reception threshold (SRT) in this case the signal-to-noise ratio for $50 \%$ word intelligibility. The participants completed three lists, one training list and two trial lists, thus testing perception of 100 words in total. All participants listened through headphones, as did the test administrator. Bilateral CI users were allowed to use both CIs, whereas bimodally aided users were required to switch off their HA but keep it plugged. This measure was taken to secure that conditions were as comparable 
as possible and to exclude any assistance from potential residual hearing. CI users as well as $\mathrm{NH}$ participants completed the test at both recording sessions ( $\mathrm{T} 1$ and $\mathrm{T} 2$ ). The rationale for testing $\mathrm{NH}$ participants twice was first to identify any effects of time and, second, to identify learning effects, which have been reported previously (Pedersen and Juhl, 2013).

\section{STATISTICAL METHODS MMN responses}

In a first step, we tested for significant MMN amplitudes by performing two-tailed one-sample $t$-tests on each of the deviant difference waves using the ttest.m function in Matlab (Mathworks, Natick, MA, USA). Following this, similar to previous MMN studies on CI users (Sandmann et al., 2010; Timm et al., 2014), we tested for main effects of group, time, and deviant type, and possible interactions between these effects by performing mixedeffects ANOVAs separately on MMN amplitudes and latencies with the between-subjects factor Group (NH and $\mathrm{CI}$ ) and the withinsubjects factors Time (T1 and T2) and deviant type (1-6). Post hoc tests were performed using Bonferroni-corrected $t$-tests.

\section{Behavioral tests}

The analysis of the behavioral data from the musical multi-feature discrimination test was performed in a separate mixed-effects ANOVA with the between-subjects factor of Group (NH and CI) and the within-subjects factors of time (T1 and T2) and deviant type (1-6).

To identify significant training effects and group differences as measured by the Dantale II test, we analyzed the SRT values using independent (between groups) and paired (within groups) $t$-tests.

Correlation analyses between EEG results, behavioral results, and clinical data were done using Spearman's product-moment test. For all tests, the level for significance was set at 0.05 , and the significant results are reported. All tests were performed in SPSS (IBM SPSS Statistics for Windows, Version 21.0. Armonk, NY, USA: IBM Corp.).

\section{RESULTS}

\section{MMN AMPLITUDES}

For the CI users, the musical multi-feature paradigm elicited significant MMNs for deviants $\mathrm{Gui}_{\mathrm{D} 3}, \mathrm{Sax}_{\mathrm{D} 4}, \mathrm{Int}_{\mathrm{D} 5}$, and RhyD6 at both T1 and T2. For the two pitch deviants, the CI users exhibited a significant $\mathrm{MMN}$ only for Pitch $1_{\mathrm{D} 1}$ and only at T1. For the $\mathrm{NH}$ listeners, our analyses showed significant MMNs for all six deviants at both times of testing, except for the T1 Int $_{\mathrm{D} 5}$ (Figures 2A-C; Tables 2 and 3 ).

Our mixed-effects analysis of the MMN amplitudes showed a significant main effect of Group, $F(1,19)=8.43 ; p=0.009$, driven by overall smaller MMN mean amplitudes in the CI users compared to the $\mathrm{NH}$ participants (mean value for combined MMNs across all deviants: CI users: T1: $-0.54 \mu \mathrm{V}, \mathrm{SD}: 0.49$, T2 $-0.47 \mu \mathrm{V}$ SD: 0.58 ; NH controls: T1 $-0.66 \mu \mathrm{V}$, SD: $0.61, \mathrm{~T} 2$ $-0.94 \mu \mathrm{V}, \mathrm{SD}: 0.58)$.). Furthermore, we found a significant main effect of deviant type $[F(5,95)=15.77 ; p<0.001]$, predominantly deriving from significantly larger amplitudes elicited by the $\operatorname{Sax}_{\mathrm{D} 4}$ compared to the other five deviants. There was also a significant interaction between Group and Time $[F(1,19)=7.3$; $p=0.014]$ driven by a significantly larger overall MMN negativity in the $\mathrm{NH}$ group at T2 compared to the CI group $(p=0.002$; $\mathrm{NH}:-0.94 \mu \mathrm{V} ; \mathrm{CI}:-0.47 \mu \mathrm{V})$. The post hoc comparison of the two groups at $\mathrm{T} 1$ was not significant. The Group by Deviant Type interaction was non-significant. Also, the three-way interaction Group $\times$ Time $\times$ Deviant Type was non-significant. Explorative $t$-tests showed a significant difference between the MMN amplitudes of the two groups for Pitch $1_{\mathrm{D} 1}[t(1,19)=-2.53 ; p=0.02]$, Gui $_{\mathrm{D} 3}[t(1,19)=-2.32 ; p<0.037]$, and Rhy 6 [ $t(1.19)=-2,38$; $p<0.028$ ], in each case driven by larger mean amplitudes in the $\mathrm{NH}$ participants compared to CI users.

\section{MMN LATENCIES}

The mixed-effects analysis on MMN latencies showed a significant main effect of Group, $F(1,19)=83.55 ; p<0.001$, driven by overall shorter MMN mean latencies in CI users than in the $\mathrm{NH}$ participants (mean value for combined MMN latencies: CI users: 127.15, SD: 31.75, NH listeners: 141.97, SD: 31.40). Furthermore, we found a significant main effect of Time $[F(1,19)=5.05$; $p=0.037$, driven by overall longer MMN latencies in both groups at T2 compared to T1 (mean latency difference: $2.43 \mathrm{~ms}$ ). Finally, we found a significant main effect of Deviant Type, $F$ (5, $95)=258.66, p<0.001$ and an interaction between Deviant Type and Group, $F(5,95)=122.6, p<0.001$. The three-way interaction Group $\times$ Time $\times$ Deviant Type was non-significant.

Post hoc t-tests for mean latencies across $\mathrm{T} 1$ and $\mathrm{T} 2$ with respect to Deviant Type showed that for CI users Gui $\mathrm{D}_{\mathrm{D} 3}$ and Rhy 6 deviants were significantly longer compared with MMN latencies in the $\mathrm{NH}$ participants $\left[\mathrm{Gui}_{\mathrm{D} 3}, t(1,19)=-5.9 ; p<0.001\right.$; Rhy 6 , $t(1,19)=-8.4, p<0.001]$. In contrast, for deviants $P i t c h 1_{D 1}$, Pitch $2_{\mathrm{D} 2}$, and Int $\mathrm{D}_{\mathrm{D}}$, we found significantly shorter latencies in the CI users compared to the $\mathrm{NH}$ group at T1and T2 [Pitch $1_{\mathrm{D} 1}, t(1$, $19)=12.58 ; p<0.001 ;$ Pitch2 2 $2, t(1,19)=9.74 ; p<0.001 ;$ Int $_{\mathrm{D} 5}$, $t(1,19)=20.71, p<0.001]$ (Figures 2A-C; Tables 2 and 3 ).

\section{BEHAVIORAL MUSICAL MULTI FEATURE DISCRIMINATION TEST}

Our mixed-effects analysis showed a significant main effect of Group, $F(1,19)=13.04 ; p=0.002$, driven by an overall $19.72 \%$ point lower score in CI users compared with NH participants. Furthermore, the analysis showed an interaction between Deviant Type and Group, $F(5,19)=13.79, p=0.001$. According to post hoc $t$-tests, this interaction was driven by significantly lower overall hit rates by the CI users for discrimination of Pitch $1_{\mathrm{D} 1}[T(5$, $19)=5.27, p=<0.001]$, Pitch $2 \mathrm{D} 2[T(5,19)=4.13, p=0.001]$, $\mathrm{Gui}_{\mathrm{D} 3}[T(5,19)=2.41, p=<0.037]$, and $\operatorname{Int}_{\mathrm{D} 5}[T(5,19)=2.63$, $p=0.023]$ compared to $\mathrm{NH}$ controls. The groups did not differ for the Sax ${ }_{\mathrm{D} 4}$ or Rhy $\mathrm{D}$ deviants (Figure 3). We found no effect of Time.

\section{DANTALE II TEST}

The CI users produced mean speech recognition threshold values of 1.0 at T1 and of 0.04 at T2, indicating a (non-significant) improvement in their ability to recognize speech in background noise. The CI users' mean SRT values were significantly higher than those of the NH participants at both T1 and T2 $(p<0.001)$ and displayed also a high variability ranging from -3.9 to $10.9 \mathrm{~dB}$ SNR. 


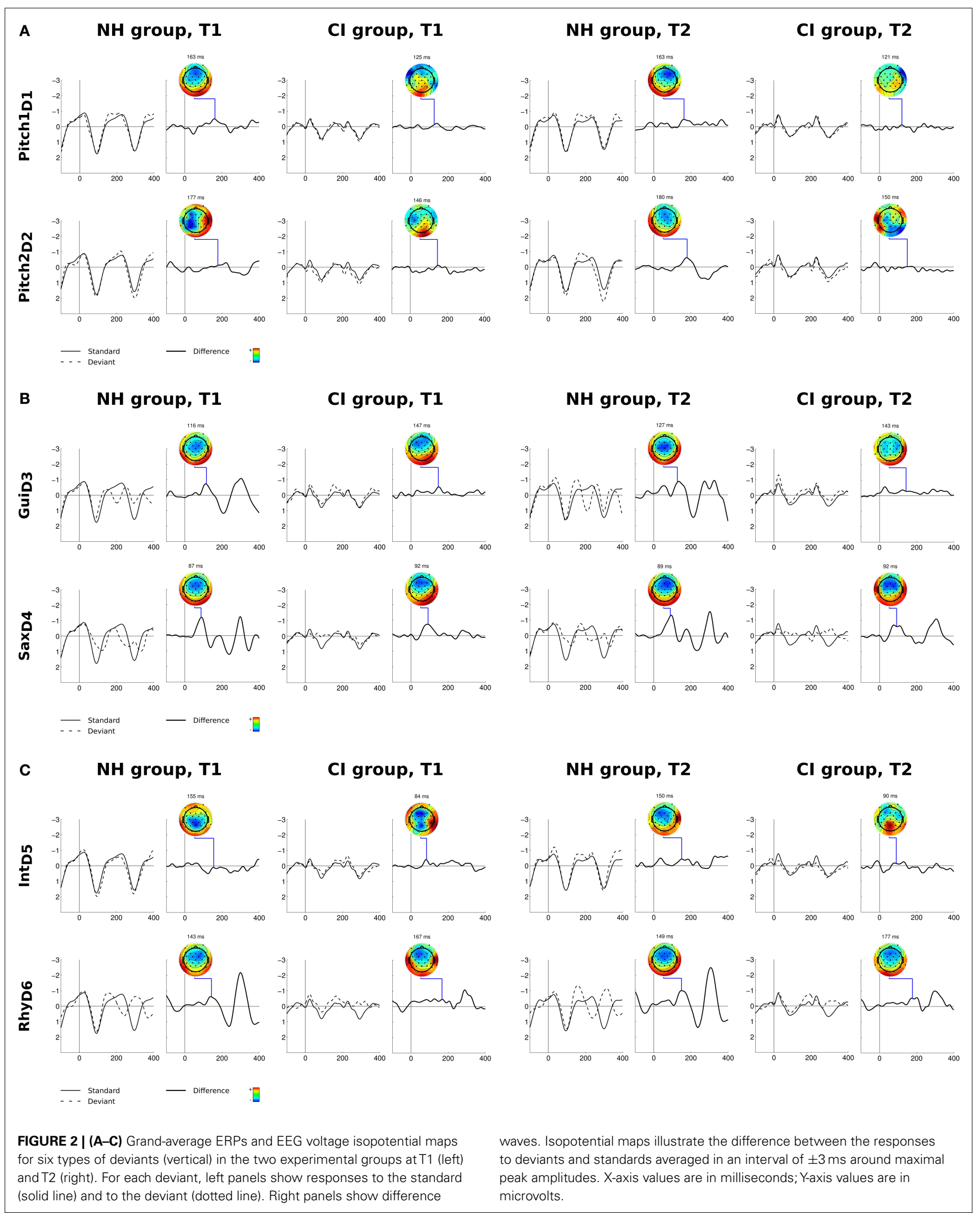


Table 2 | Amplitudes and latencies of the MMN in response to different musical features in $\mathrm{Cl}$ users at T1 and T2.

\begin{tabular}{|c|c|c|c|c|c|c|c|c|c|}
\hline \multicolumn{2}{|l|}{ Cl users } & \multicolumn{4}{|c|}{ T1 results } & \multicolumn{4}{|c|}{ T2 results } \\
\hline Deviant & $\begin{array}{l}\text { Interval } \\
\text { (ms) }\end{array}$ & $\begin{array}{l}\text { Peak amplitude } \\
\qquad(\mu \mathrm{V})\end{array}$ & $t$ & SD & $\begin{array}{l}\text { Latency } \\
\text { (ms) (SD) }\end{array}$ & $\begin{array}{l}\text { Peak amplitude } \\
\qquad(\mu \mathrm{V})\end{array}$ & $t$ & SD & $\begin{array}{l}\text { Latency } \\
\text { (ms) (SD) }\end{array}$ \\
\hline Pitch1D1 & $103-143$ & -0.45 & $-3.49^{* *}$ & 0.43 & 125 (11.8) & -0.27 & -1.54 & 0.58 & $121(9.7)$ \\
\hline Pitch2D2 & 128-168 & -0.19 & -1.18 & 0.55 & $146(10.2)$ & -0.22 & -1.72 & 0.42 & $150(11.7)$ \\
\hline GuidD3 & $125-165$ & -0.63 & $-6.41^{* *}$ & 0.33 & 147 (8.8) & -0.45 & $-3.80 * *$ & 0.39 & $143(11.8)$ \\
\hline $\mathrm{Sax}_{\mathrm{D} 4}$ & $72-112$ & -0.88 & $-6.06^{* *}$ & 0.51 & $92(11.0)$ & -0.88 & $-6.55^{* *}$ & 0.44 & $92(12.7)$ \\
\hline $\operatorname{lnt} t_{D 5}$ & 67-107 & -0.42 & $-3.10^{*}$ & 0.45 & $84(8.0)$ & -0.36 & $-2.34^{*}$ & 0.51 & 90 (11.6) \\
\hline RhyD6 & 152-192 & -0.57 & $-5.24^{* *}$ & 0.36 & $167(10.2)$ & -0.63 & $-4.62^{* *}$ & 0.45 & $177(7.2)$ \\
\hline
\end{tabular}

$\left.{ }^{*} p=0.01 ;{ }^{*} p<0.001\right)$.

Table 3 | Amplitudes and latencies of the MMN in response to different musical features in normal-hearing controls at T1 and T2.

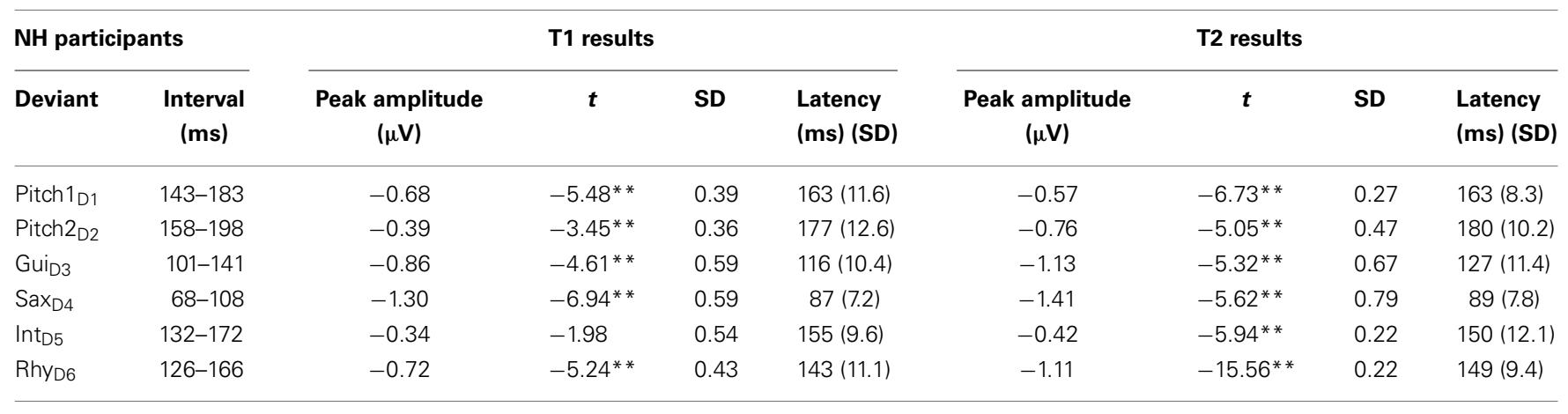

${ }^{*} p=0.01 ;{ }^{*} p<0.001$.

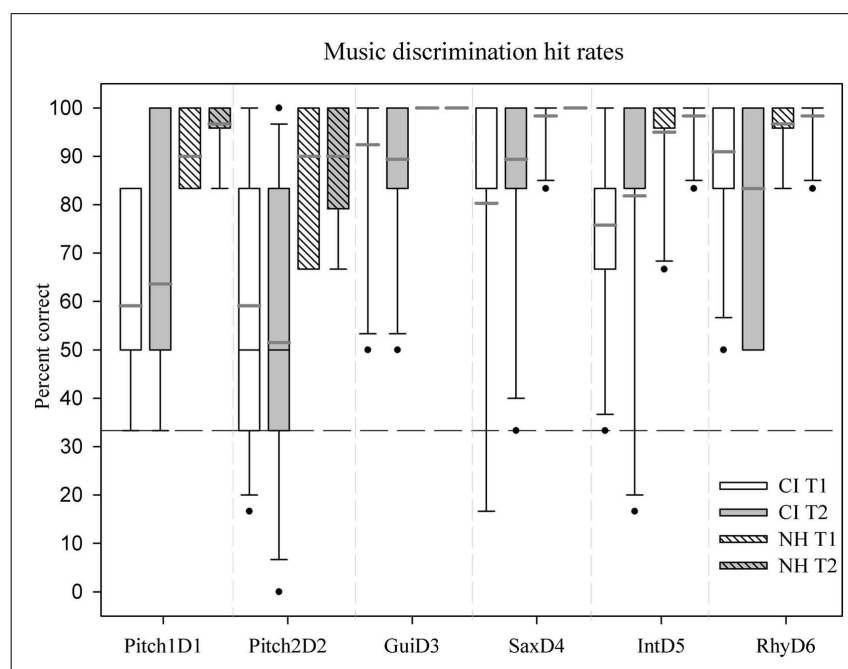

FIGURE 3 | Box plot showing mean hit rates of the two groups for the six deviants at T1 and T2. Whiskers (error bars) above and below the box indicate the 90th and 10th percentiles. Solid black line represents the median, gray line represents the mean. Dots represent outlying points. Dashed line represents chance level.

The mean SRT for NH participants was -6.9 at $\mathrm{T} 1$ and -7.7 at $\mathrm{T} 2$, which represented a significant improvement $[t(1,9)=3.31$, $p=0.009]$ (Figure 4).

\section{CORRELATIONS}

Correlation analyses were performed for CI users between MMN amplitudes and latencies and behavioral music discrimination scores and Dantale II T2 results and demographic data. Because our ANOVAs showed no main effect of Time, we computed values that were averaged across T1 and T2 for MMN amplitudes and behavioral music discrimination data.

For the MMN data, a significant positive association was found between mean amplitudes for the Gui $\mathrm{D}_{3}(r=0.798)$ and RhyD6 $(r=0.605)$ and age, indicating that younger CI users had larger MMN responses than older CI users for these two deviants. Furthermore, we found a significant negative association between hearing age (implant experience) and mean latency for the RhyD6 $(r=-0.838)$, indicating that CI users with higher hearing age had MMN responses with shorter latency for this deviant (Figure 5). A similar non-significant association was found for the $\operatorname{Sax}_{\mathrm{D} 4}$ deviant $(r=-0.592$, $p=0.055$ ).

Hit rates for behavioral discrimination of the six different musical deviants showed a general positive association with each other. Significant correlations were found between discrimination of IntD5 and Pitch1 $1_{\mathrm{D} 1}(r=0.699)$, Gui ${ }_{\mathrm{D} 3}(r=0.642)$, Sax 4 $(r=0.907)$, and Rhy $6(r=0.789)$ and between Rhy 6 and Pitch2 $22(r=0.665)$ and $\operatorname{Sax}_{\mathrm{D} 4}(r=0.807)$. Further associations were found between behavioral discrimination scores and Dantale II SRTs, in all cases, however, driven by an extraordinarily high SRT by a single outlier. 


\section{DISCUSSION}

The current study measured behavioral and electrophysiological correlates of music perception in prelingually deaf adolescents before and after a 2-week music training program. A group of age-matched NH listeners served as controls. Overall, the results revealed smaller MMN amplitudes and shorter MMN latencies in

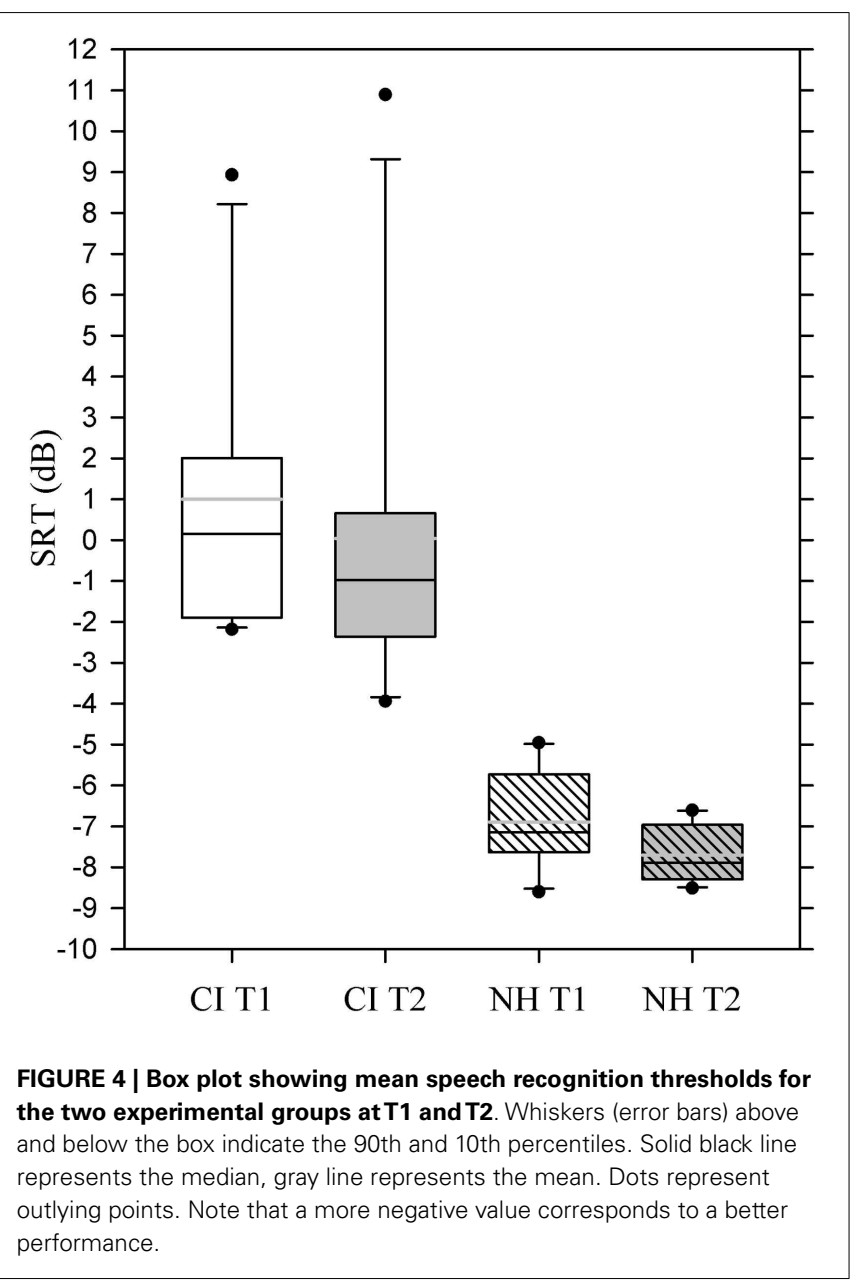

CI users than in NH listeners. More specifically, the adolescent CI users showed robust MMN responses for deviations in timbre, intensity, and rhythm. For pitch deviants, we found no consistent MMNs in CI users, which was also reflected in the CI users' poor hit rates for behavioral pitch discrimination. The findings suggest that even though these adolescents received their implants beyond the optimal age for cochlear implantation (Kral and Sharma, 2012) and have formed their perception of sound solely through the implant, their auditory pathways have been sufficiently developed to allow some discrimination of details in music, predominantly within timbre, timing, and intensity. The study complements previous MMN studies with adult and pediatric CI users (Sandmann et al., 2010; Zhang, 2011; Torppa et al., 2012, 2014), showing potential ability also in prelingually deaf, late-implanted adolescent CI users to process features of music, even when embedded in a complex auditory context.

Consistent with our hypothesis, we found significantly diminished overall amplitudes in the CI users compared to NH controls. The difference, however, reflected differential responses depending on deviant type, with smaller MMN amplitudes elicited by the

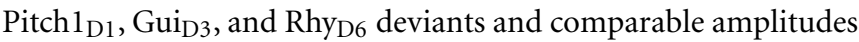
elicited by the $\mathrm{Sax}_{\mathrm{D} 4}$ and $\mathrm{Int}_{\mathrm{D} 5}$ deviants. In line with this, we found significantly poorer overall behavioral discrimination scores, which confirm that $\mathrm{MMN}$ responses for changes in various kinds of stimuli are reflected in discrimination accuracy (Näätänen et al., 2007). Contrary to our hypothesis, we found significantly shorter overall MMN latencies in the CI users compared to $\mathrm{NH}$ peers. Again the difference was linked to deviant type; Gui ${ }_{\mathrm{D} 3}$ and RhyD6 deviants showed significantly longer latencies, whereas the Int and the two pitch deviants were elicited significantly earlier than those of the NH reference. Latencies for pitch, however, should be judged with caution, given the fact that the pitch MMNs were nonsignificant for Pitch $1_{\mathrm{D} 1}$ at T2 and for Pitch2 2 at both time points.

\section{MUSIC TRAINING}

For most of the young CI users, this project was their first experience with structured and targeted music making and certainly challenging. Indeed, they generally responded with great enthusiasm to the different exercises and tasks and also displayed a marked progress in their musical competences. Nevertheless, in contrast
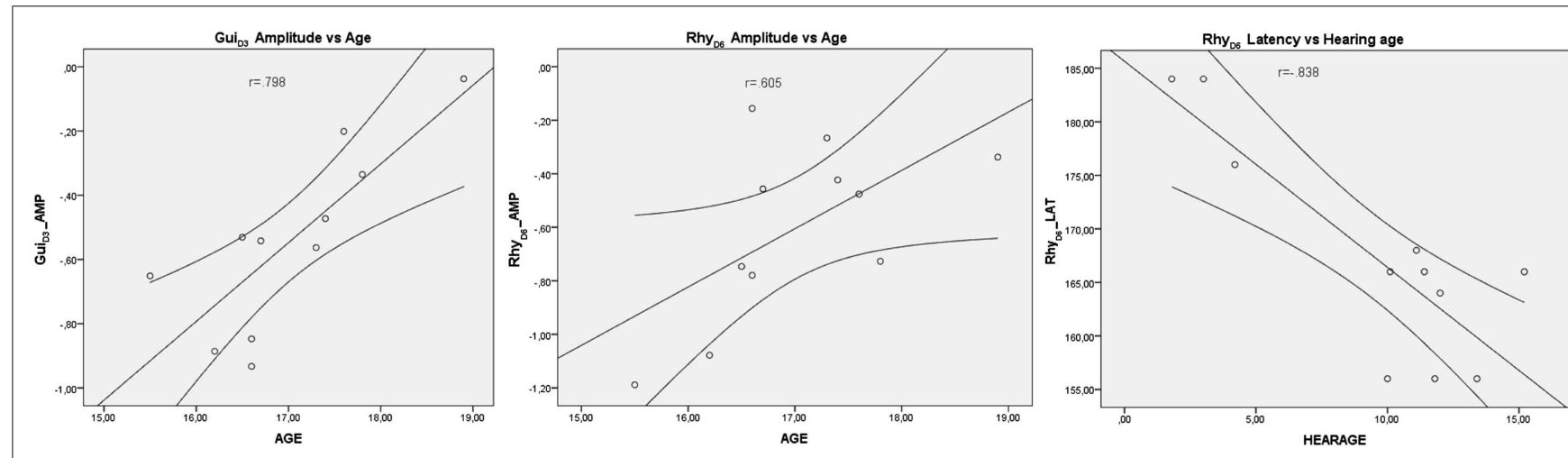

FIGURE 5 | Scatter plots illustrating the correlation between the mean MMN amplitude to the Gui $_{D 3}$ and age (left panel), mean amplitude to the Rhy ${ }_{D 6}$ deviant and age (middle panel), and mean MMN latency for the Rhy ${ }_{\mathrm{D} 6}$ deviant and hearing age (=implant experience) in the adolescent $\mathrm{Cl}$ users. 
to our hypothesis, we were unable to observe any progress in the young CI users' discrimination skills at either a neuronal or behavioral level. This lack of progress could be due to the brevity of the program. Moreover, the broad-spectrum and music-making nature of the training may have been insufficiently focused to reliably strengthen the specific auditory skills in demand for the tests in such a short period of time. It is important to emphasize, however, that because of interference with the participants' school activities, an extended training period was not an option and that the music-making approach was deliberately chosen to ensure maximum appeal to the participants. Evenly important, according to self-report, the CI participants spent much less time training with the musical quizzes than requested. Despite instant feedback and progressive design, the quizzes offered little excitement in comparison with current computer games and may simply have appeared less appealing. Future studies should investigate the possible advantages of applications, preferably for smart phones or tablet computers, which offer auditory training of music discrimination skills in an adaptive, socially interactive, and game-like design (Lee and Hammer, 2011).

Contrary to our predictions, we found an overall progress in MMN amplitude in the NH group, who received no music training. We could speculate that $\mathrm{NH}$ subjects show training effects simply by being a second time exposed to the same sound stimulation (Paukkunen, 2011). Instead, CI users, even if they had a musical training, did not show any advantage at T2, probably as a consequence of their deficits in musical sound processing. To be visible, the exposure to sounds in CI users should most likely be very long and intensive, whereas in normal subjects some transient neural effects are observable even already after 20 min of discrimination training (Jäncke et al., 2001; Brattico et al., 2003; Lappe et al., 2011).

\section{RHYTHM}

Previous behavioral studies with postlingually deaf CI users have documented that discrimination of complex rhythm is difficult (Leal et al., 2003; Kong et al., 2004; Drennan and Rubinstein, 2008). In that respect, we were encouraged to find that the adolescent $\mathrm{CI}$ users were able to produce significant $\mathrm{MMN}$ responses to a change in rhythm as fast as $60 \mathrm{~ms}$ and produce discrimination scores that were not significantly different from the $\mathrm{NH}$ reference. This is an indication of the ability of these young CI users to extract fast temporal information despite prelingual deafness and late implantation, as well as the accuracy with which timing features are transmitted in current CI technology. Ability to discriminate rhythm may assist young CI users in general when listening to music, especially for genres that tend to have strong rhythmic elements paired with lyrics (Gfeller et al., 2012). Moreover, poor perception of rhythm has been associated with poor perception of syllable stress and dyslexia (Overy, 2003; Overy et al., 2003; Huss, 2011), and it is possible that training of rhythm, on a long-term, could form a beneficial part in auditory-oral therapy for young CI users (Looi and She, 2010; Petersen et al., 2012).

Our results are in contrast with Timm et al. (2014) who found no robust MMN response to the rhythm deviant in their adult CI users. The authors speculated that one of the sources to this absence of MMN could possibly be that the relatively small deviation of $60 \mathrm{~ms}$ was too difficult to extract, especially when embedded in a complex auditory scene. There may be several sources to the discrepancy between the two studies. First, the CI users in the present study were significantly younger (mean age 17 vs. 43.5 years), which may influence neural processing of auditory stimuli. Second, the adolescent CI users all used the most updated implant device in contrast to the adult CI users' selection of brands and models, which might result in some differences in timing accuracy. A minor difference in the way the rhythm deviant was presented in the two studies may also have contributed to the different results. In the present study, the position of the fourth note was preserved, thus leaving the metric pulse uninterrupted. In the Timm et al. (2014) study, the position of the fourth note was altered in accordance with the early third note, thereby shifting the metric pulse. Thus, the rhythm deviant in the present study deviates in three ways. First, it cuts the preceding note short, which could be perceived as a deviation of duration. Second, the third note comes early, violating the rhythmic flow and, third, the fourth note comes late, caused by the longer gap between notes 3 and 4 . By inspecting the difference wave plots for the rhythm deviant (Figure 2C), it appears that this multifaceted deviation evokes not only a significant MMN in the 143-173 ms window after stimulus onset but also a consistent and even stronger negative peak around $325 \mathrm{~ms}$. This effect is identical and consistent across groups and time points and we speculate that it reflects a second MMN in response to the late fourth note.

\section{TIMBRE}

Both the guitar and the saxophone deviants elicited significant brain responses in our two experimental groups. This is in contrast to findings by Torppa et al. (2012) who in a study with CI and $\mathrm{NH}$ children found significant MMNs only to a large change from piano to cymbal but not to changes from piano to violin or to cembalo. They did, however, find indications of a general improvement with age in the children's ability to detect changes between instruments, which could partly explain this discrepancy. Our findings are in line with Timm et al. (2014) who found similar strong MMN responses to timbre changes in postlingually deaf adult CI users. Interestingly, in both studies the saxophone deviant showed the largest effect compared to the remaining deviants and amplitude and latency that were not significantly different from those of NH listeners. It should be emphasized, however, that the latency of the MMN for this particular deviant was quite different in the two studies, elicited around $92 \mathrm{~ms}$ in the present and around $165 \mathrm{~ms}$ in the Timm et al. (2014) study. Since both the stimuli and the experimental settings were identical, we speculate that differences in age may be the primary source of this difference in timing.

As opposed to the saxophone deviant, CI users' $\mathrm{MMN}$ responses to the guitar deviant showed significantly smaller amplitudes and significantly longer latencies than those of $\mathrm{NH}$ controls, indicating reduced discrimination accuracy. The neurophysiological findings were reflected in behavioral performance in which the CI users produced discrimination scores, which were comparable to the $\mathrm{NH}$ level for the saxophone but not for the guitar deviant. This suggests that the sound of a saxophone, which is characterized by 
a slow attack and a soft tone, represents a larger deviation from the piano tone than the sharp distinct sound of the guitar. Moreover, in an MMN study, which is based on the theory of predictive coding (Baldeweg, 2006), an unexpected occurrence of a saxophone sound in a stream of piano notes represents not only a change of timbre but also a change in timing and intensity, which could also partly explain the observed difference.

So are adolescent CI users as good or almost as good as NH peers in discrimination of timbre? No, probably not. Discrimination of timbre involves perception of several acoustic parameters, particularly the temporal envelope (rise time, duration, and decay) and harmonic spectrum of a sound, and is usually poor in CI users (Gfeller et al., 2002a; McDermott and Looi, 2004; Drennan and Rubinstein, 2008; Spitzer et al., 2008; Timm et al., 2012). The fact that the adolescent CI users were able to detect changes in timbre does not necessarily mean that they would be able to recognize a musical instrument. It does, however, indicate that they possess some basic prerequisites for developing this skill and that the implant transmits sufficient spectral information to allow detection of changes in timbre (Koelsch, 2004). Previous studies have showed enhanced abilities to discriminate timbre after computerassisted training (Fujita and Ito, 1999; Leal et al., 2003; Pressnitzer et al., 2005; Driscoll et al., 2009) and long-term individual training (Petersen et al., 2012). Improved perception of timbre may add positively to the esthetic enjoyment of music listening and may also be beneficial in other aspects of listening such as recognition of gender or speaker in auditory-only acoustic communication, which are notoriously challenging with CIs (Vongphoe and Zeng, 2005).

\section{PITCH}

Except for the Pitch $1_{\mathrm{D} 1}$ deviant at T1, the CI group did not exhibit significant MMN responses to changes in pitch of neither two nor four semitones and produced pitch discrimination scores, which were significantly below the NH level. This pitch discrimination deficit may indicate that the neuronal connections of the auditory pathways were not established in the appropriate time window of opportunity, leaving the potential for developing pitch processing abilities very limited (Sharma et al., 2005; Sharma, 2006). Despite ability to produce significant MMNs for pitch deviants, the adult CI users in the study by Timm et al. (2014) showed significantly diminished amplitudes, longer latencies, and lower hit rates for the two and four semitones pitch deviants compared to $\mathrm{NH}$ controls. This indicates that, at least for small pitch change detection, the advantages of postlingually deafened CI users, who rely on auditory skills developed prior to their hearing loss, over prelingually deaf adolescent CI users, whose auditory development is based exclusively on implant experience, may be rather small.

Interestingly, Torppa et al. (2012) in a recent study found magnitude and timing of MMN responses to three and seven semitone changes of pitch in early-implanted CI children that were comparable to those of $\mathrm{NH}$ controls. The authors suggested that harmonic components of the presented piano tones may be sufficiently separated in frequency to allow accessibility of spectral cues to a change in pitch to the CI children. While the children in the Torppa et al.' study had a mean age at switch-on of 21.5 months (range $14-37 \mathrm{~m}$ ), the adolescents in the present study were implanted significantly later (mean age at switchon: 7.4 years). We speculate that the delayed stimulation of the auditory system is the primary cause of the poor pitch processing observed in the adolescent CI users. Furthermore, the previous study used a multi-feature MMN paradigm, which presented repeated piano tones in contrast to the present study, which presented deviants in a complex musical context and randomly changing keys.

We observed a significant $\mathrm{MMN}$ for the $\mathrm{Pitch}_{\mathrm{D} 1}$ at $\mathrm{T} 1$ but not at T2, implying a reverse effect of the training. However, considering the intensive focus on pitch and melody included in both the singing and ear training activities, we hardly believe that is the case. More likely, the inconsistent pitch MMNs reflect the suboptimal recording conditions and possible variability across sessions in participant behavior, which may have prevented the weak pitch responses from passing the statistical thresholds. Alternatively, pitch MMNs were elicited but could not be identified due to overlap by other potentials. Finally, the rather short SOA used here prevented identifying a latency longer than $200 \mathrm{~ms}$. Considering that the $\mathrm{NH}$ children showed MMN latencies to pitch deviants close to $200 \mathrm{~ms}$, it may well be that we simply missed it.

\section{INTENSITY}

Electrical hearing produces a much narrower dynamic range than acoustic hearing (Galvin et al., 2007; Veekmans et al., 2009). We were therefore surprised to find $\mathrm{MMN}$ responses to the $\mathrm{Int}_{\mathrm{D} 5}$ deviant, which were not significantly different in amplitude from those of the NH listeners. It should be emphasized, however, that the $\mathrm{NH}$ responses were surprisingly weak for these deviant and non-significant at T2, indicating a generally small effect of this deviation. Furthermore, although significantly poorer than the $\mathrm{NH}$ reference, the CI users' hit rates for discrimination of intensity were well above chance. This indicates that despite the limited dynamics of the implant, the $12 \mathrm{~dB}$ decrement in intensity is transmitted reliably even in prelingually deaf adolescent CI users. The results are partly consistent with a previous MMN level-study with adult CI users, in which Sandmann et al. (2010) found significant MMN responses to a $12 \mathrm{~dB}$ intensity decrement but not to two smaller 4 and $8 \mathrm{~dB}$ intensity decrements. Future studies should investigate discrimination of changes of intensity in adolescent CI users in more detail.

While our two experimental groups produced similar but small $\mathrm{MMN}$ amplitudes in response to the Int $_{\mathrm{D} 5}$ deviant, the latencies differed significantly. The MMNs of the CI users peaked around $84 \mathrm{~ms}$ while those of the NH listeners peaked around $150 \mathrm{~ms}$. This difference may reflect different processing of this particular deviant. However, as with the MMN responses for pitch, we cannot exclude the possibility that the latency values for intensity in the CI group may reflect activity that is different from the activity reflected in the later peaks among $\mathrm{NH}$ participants.

\section{SPEECH PERCEPTION IN NOISE}

The marked improvement in the CI users' SRT s suggested a transfer effect from the music training. The similar and significant progress in the non-trained $\mathrm{NH}$ group, however, indicates that these improvements are the results of a test learning effect, as seen in previous studies (Pedersen and Juhl, 2013). The Dantale 
II test requires the ability to identify words in spoken sentences in background noise and subsequently match these with a matrix of optional words on a computer screen, a complex task that relies on both reading skills and working memory and may benefit from previous exposure. These requirements may also explain the huge variability observed in the CI group reflecting possible differences in the participants' linguistic and cognitive development (Burkholder and Pisoni, 2003). Naturally, the variance may also reflect other factors such as history of hearing loss and CI functionality. None such predictive factors, however, were identified in our correlational analyses.

\section{MUSICAL MULTI-FEATURE PARADIGM}

Our results indicate that the fast, musical, multi-feature paradigm presenting deviants embedded in a complex musical pattern can elicit distinct MMNs not only in postlingually deaf adults but even in prelingually deaf adolescent CI users. Since MMNs are elicited pre-attentively with no behavioral task, this paradigm may be used for objective evaluation of CI users' auditory skills in general and ability to discriminate musical sounds in particular. Because it is fast with a recording time of only $20 \mathrm{~min}$ and highly flexible with regard to both the nature and the deviation magnitude of the properties which it investigates, this paradigm could be a useful tool for assessing auditory rehabilitation following cochlear implantation. In a clinical context, MMN responses could be of relevance as an objective marker for measuring auditory discrimination abilities in CI patients, especially pediatric CI users, whose assessment of auditory discrimination and implant outcome is challenging. The paradigm does, however, run at a fast pace and a future revision should evaluate the effects of a reduced tempo, allowing analysis of effects in the 200-400 ms, particularly the P3a (Torppa et al., 2012).

\section{THE IMPACT OF HEARING AGE}

The adolescent CI users in our study represented a huge range of age at implantation as well as communication background. Nevertheless, apart from the indication of an association between higher hearing age and shorter latencies for rhythm and saxophone, we found none of these factors predictive of either neurophysiological or behavioral performance. Especially with regard to the behavioral tests, this suggests that skills associated with cognition, concentration, attention, and memory may have a stronger impact than implant experience and prior use of sign language. As an interesting single case, CI 5, who is profoundly deaf, raised as a sign language user and who received his implant at the age of 9 years was able to score in the high average level of his group in both speech and music tests.

\section{LIMITATIONS}

Recording and analyzing EEG with CI users represent a number of challenges. Due to the position of the implant, some electrodes cannot be used, resulting in a number of interpolated channels. Furthermore, due to the electric signal from the implant, it is necessary to use elaborate preprocessing procedures to reduce the CI artifact (Sandmann et al., 2009; Viola et al., 2011), allowing interpretation of the resulting evoked potentials of interest. Finally, in this particular study, recordings were done in the field, thus potentially degrading the signal-to-noise ratio as compared to recordings made in the shielded settings of the laboratory. In sum, these challenges may have resulted in data, which were less consistent than desired. Furthermore, measuring ERPs in a group of healthy individuals and a special group such as CI users implies an intrinsic difficulty of picking up the same peak for both groups. We cannot preclude that the applied peak-identification method, which identified MMN peaks algorithmically and separately in the two groups, erroneously may have led us to peaks from the two groups that in fact belonged to different ERP components.

The adolescent CI users in this study belong to the first generation of children who were offered CIs. Since, at the time, neo-natal hearing screening was not a standard procedure and some concerns about the safety of the surgery existed, they were in general both diagnosed and implanted later in childhood than is typical today. Therefore, they may not be fully representative of the future generations of early-implanted adolescents. We will, however, argue that the study and its findings are relevant, particularly considering the considerable number of teenagers worldwide making up this generation.

\section{SUMMARY AND CONCLUSION}

Our findings provide novel insight on neural processing of musical sounds in a new generation of deaf adolescents, who have grown up with the assistance of CIs. The results showed that despite prelingual deafness and late implantation, adolescent CI users possess prerequisites for some discrimination of musical sounds, as indicated by their significant MMN responses particularly to changes in timbre, rhythm, and intensity. Compared to a $\mathrm{NH}$ reference, however, the CI users' general discrimination abilities were characterized by significantly weaker brain responses and poorer behavioral performance. This was particularly true for their discrimination of small changes in pitch, which showed a severe deficit, reflected in inconsistent brain responses, and poor behavioral performance. Evidently, perception of music - especially melody - is degraded in these adolescent CI users, as also signified by the challenges observed in relation to singing. This, however, does not necessarily reduce music appreciation. Unlike postlingually deaf adult CI users, prelingually deaf CI users make no comparisons with previous music listening experience and may be quite satisfied with the representation provided by the implant, perceiving possibly particularly the rhythmic content of music (Gfeller et al., 2012). The lack of findings with an ear training program lasting only 2 weeks in CI users shows their refractoriness to auditory interventions. Thus, we encourage future research on the effects of longitudinal music training, preferably involving a combination of music making and training applications offering an adaptive and game-like interface. As observed here, the great compliance and enthusiasm of the participants indicate that such measures could be relatively easily implemented.

\section{ACKNOWLEDGMENTS}

The authors wish to acknowledge all of the participants and their parents for their unrestricted commitment to the study as well as the staff at Frijsenborg Efterskole for invaluable help and support in organizing and scheduling tests and training. Furthermore, they wish to thank Susanne Mai, Minna Sandahl, and 
Anne Marie Ravn from the Department of Audiology, Aarhus University Hospital and Jesper Dahl at Gentofte Hospital for provision of clinical data and Professor Therese Ovesen at the ENT department of Aarhus University Hospital for her help and support. Finally, they thank Nynne Horn, Andreas Højlund Nielsen, and Martin Dietz for assistance and counseling on EEG recording and analysis. EEG facilities were generously provided by Center of Functionally Integrative Neuroscience, Aarhus University Hospital. This work was supported by a grant from the Danish Ministry of Culture's Research Foundation (Bjørn Petersen) and by the Cluster of Excellence "Hearing4all" (Pascale Sandmann).

\section{REFERENCES}

Agrawal, D. (2013). Electrophysiological responses to emotional prosody perception in cochlear implant users. NeuroImage Clin. 2, 229-238. doi:10.1016/j.nicl.2013. 01.001

Archbold, S., Sach, T., O’Neill, C., Lutman, M., and Gregory, S. (2008). Outcomes from cochlear implantation for child and family: parental perspectives. Deaf. Educ. Int. 10, 120-142. doi:10.1097/MAO.0b013e3182522906

Baldeweg, T. (2006). Repetition effects to sounds: evidence for predictive coding in the auditory system. Trends Cogn. Sci. 2006, 93-94. doi:10.1016/j.tics. 2006.01.010

Bosco, E. (2012). Long term results in late implanted adolescent and adult CI recipients. Eur. Arch. Otorhinolaryngol. 270, 2611-2620. doi:10.1007/s00405-0122264-4

Brattico, E., Tervaniemi, M., and Picton, T. W. (2003). Effects of brief discriminationtraining on the auditory N1 wave. Neuroreport 14, 2489-2492. doi:10.1097/ 00001756-200312190-00039

Burkholder, R. A., and Pisoni, D. B. (2003). Speech timing and working memory in profoundly deaf children after cochlear implantation. J. Exp. Child Psychol. 85, 63-88. doi:10.1016/S0022-0965(03)00033-X

Cooper, W. B., Tobey, E., and Loizou, P. C. (2008). Music perception by cochlear implant and normal hearing listeners as measured by the Montreal battery for evaluation of Amusia. Ear Hear. 29, 618-626. doi:10.1097/AUD. 0b013e318174e787

Debener, S. (2008). Source localization of auditory evoked potentials after cochlear implantation. Psychophysiology 45, 20-24. doi:10.1111/j.1469-8986. 2007.00610.x

Debener, S., Thorne, J. D., Schneider, T. R., and Viola, F. (2010). "Using ICA for the analysis 50 of multichannel EEG data," in Simultaneous EEG and fMRI: Recording, Analysis, and Application, Vol. 1, eds M. Ullsperger and S. Debener (New York, NY: Oxford University Press), 121-134.

Delorme, A. (2004). EEGLAB: an open source toolbox for analysis of single-trial EEG dynamics including independent component analysis. J. Neurosci. Methods 134, 9-21. doi:10.1016/j.jneumeth.2003.10.009

Drennan, W. R., and Rubinstein, J. T. (2008). Music perception in cochlear implant users and its relationship with psychophysical capabilities. J. Rehabil. Res. Dev. 45, 779-789. doi:10.1682/JRRD.2007.08.0118

Driscoll, V. D., Oleson, J., Jiang, D., and Gfeller, K. (2009). Effects of training on recognition of musical instruments presented through cochlear implant simulations. J. Am. Acad. Audiol. 20, 71-82. doi:10.3766/jaaa.20.1.7

Fu, Q. J., and Galvin, J. J. III (2008). Maximizing cochlear implant patients' performance with advanced speech training procedures. Hear. Res. 242, 198-208. doi:10.1016/j.heares.2007.11.010

Fujita, S., and Ito, J. (1999). Ability of nucleus cochlear implantees to recognize music. Ann. Otol. Rhinol. Laryngol. 108, 634-640. doi:10.1177/ 000348949910800702

Galvin, J. J., Fu, Q. J., and Nogaki, G. (2007). Melodic contour identification by cochlear implant listeners. Ear Hear. 1169, 518-533. doi:10.1097/01.aud. 0000261689.35445 .20

Geers, A., Tobey, E., Moog, J., and Brenner, C. (2008). Long-term outcomes of cochlear implantation in the preschool years: from elementary grades to high school. Int. J. Audiol. 47, S21-S30. doi:10.1080/14992020802339167

Gfeller, K., Driscoll, V., Smith, R. S., and Scheperle, C. (2012). The music experiences and attitudes of a first cohort of prelingually-deaf adolescents and young adults CI recipients. Semin. Hear. 33, 346-360. doi:10.1055/s-0032-1329224
Gfeller, K., and Lansing, C. R. (1991). Melodic, rhythmic, and timbral perception of adult cochlear implant users. J. Speech Hear. Res. 34, 916-920. doi:10.1044/jshr.3404.916

Gfeller, K., Mehr, S. A., Woodworth, G., and Knutson, J. (2002a). Effects of frequency, instrumental family, and cochlear implant type on timbre recognition and appraisal. Ann. Otol. Rhinol. Laryngol. 111, 349. doi:10.1177/ 000348940211100412

Gfeller, K., Witt, S., Adamek, M., Mehr, M., Rogers, J., Stordahl, J., et al. (2002b). Effects of training on timbre recognition and appraisal by postlingually deafened cochlear implant recipients. J. Am. Acad. Audiol. 13, 132-145.

Gfeller, K., Olszewski, C., Rychener, M., Sena, K., Knutson, J. F., Witt, S., et al. (2005). Recognition of "real-world" musical excerpts by cochlear implant recipients and normal-hearing adults. Ear Hear. 26, 237-250. doi:10.1097/00003446200506000-00001

Gfeller, K., Turner, C., Oleson, J., Zhang, X., Gantz, B., Froman, R., et al. (2007). Accuracy of cochlear implant recipients on pitch perception, melody recognition, and speech reception in noise. Ear Hear. 28, 412-423. doi:10.1097/AUD. ob013e3180479318

Gfeller, K., Witt, S., Stordahl, J., Mehr, M., and Woodworth, G. (2000a). The effects of training on melody recognition and appraisal by adult cochlear implants recipients. J. Acad. Rehabil. Audiol. 33, 115-138.

Gfeller, K., Christ, A., Knutson, J. F., Witt, S., Murray, K. T., and Tyler, R. S. (2000b) Musical backgrounds, listening habits, and aesthetic enjoyment of adult cochlear implant recipients. J Am. Acad. Audiol 11, 390-406.

Gilley, P. M. (2006). Minimization of cochlear implant stimulus artifact in cortical auditory evoked potentials. Neurophysiol. Clin. 117, 1772-1782. doi:10.1016/j. clinph.2006.04.018

Hansen, N.-H. M. (2012). Langtidsstudie af unge hørehømmede efter Frijsenborg Efterskole. CEFU, Center for Ungdomsforskning: Danmarks Pædagogiske Universitetsskole. Aarhus: Aarhus University. [In Danish].

Harris, M., and Terlektsi, E. (2011). Reading and spelling abilities of deaf adolescents with cochlear implants and hearing aids. J. Deaf Stud. Deaf Educ. 16, 24-34. doi:10.1093/deafed/enq031

Huss, M. (2011). Music, rhythm, rise time perception and developmental dyslexia: perception of musical meter predicts reading and phonology. Cortex 47, 674-689. doi:10.1016/j.cortex.2010.07.010

Jäncke, L., Gaab, N., Wüstenberg, T., Scheich, H., and Heinze, H. J. (2001). Shortterm functional plasticity in the human auditory cortex: an fMRI study. Brain Res. Cogn. Brain Res. 12, 479-485. doi:10.1016/S0926-6410(01)00092-1

Koelsch, S. (2004). Music perception in cochlear implant users: an eventrelated potential study. Neurophysiol. Clin. 115, 966-972. doi:10.1016/j.clinph. 2003.11.032

Kong, Y. Y., Cruz, R., Jones, J. A., and Zeng, F. G. (2004). Music perception with temporal cues in acoustic and electric hearing. Ear Hear. 25, 173-185. doi:10.1097/01.AUD.0000120365.97792.2F

Kral, A., and Sharma, A. (2012). Developmental neuroplasticity after cochlear implantation. Trends Neurosci. 35, 111-122. doi:10.1016/j.tins.2011.09.004

Lappe, C., Trainor, L. J., Herholz, S. C., and Pantev, C. (2011). Cortical plasticity induced by short-term multimodal musical rhythm training. PLoS ONE 6:e21493. doi:10.1371/journal.pone.0021493

Lassaletta, L., Castro, A., Bastarrica, M., Perez-Mora, R., Herran, B., Sanz, L., et al (2008). Changes in listening habits and quality of musical sound after cochlear implantation. Otolaryngol. Head Neck Surg. 138, 363-367. doi:10.1016/j.otohns. 2007.11.028

Leal, M. C., Shin, Y. J., Laborde, M. L., Calmels, M. N., Verges, S., Lugardon, S., et al. (2003). Music perception in adult cochlear implant recipients. Acta Otolaryngol. 123, 826-835. doi:10.1080/00016480310000386

Lee, J., and Hammer, J. (2011). Gamification in education: what, how, why bother? Acad. Exch. Q. 15. Available at: http://www.gamifyingeducation.org/files/ Lee-Hammer-AEQ-2011.pdf

Loizou, P. C. (1999). Introduction to cochlear implants. IEEE Eng. Med. Biol. Mag. 18, 32-42. doi:10.1109/51.740962

Looi, V., and She, J. (2010). Music perception of cochlear implant users: a questionnaire, and its implications for a music training program. Int. J. Audiol. 49, 116-128. doi:10.3109/14992020903405987

McDermott, H. J. (2004). Music perception with cochlear implants: a review. Trends Amplif. 8, 49-82. doi:10.1177/108471380400800203

McDermott, H. J., and Looi, V. (2004). Perception of complex signals, including musical sounds, with cochlear implants. Int. Congr. Ser. 1273, 201-204. doi:10.1016/j.ics.2004.08.034 
Moore, D. R., and Shannon, R. V. (2009). Beyond cochlear implants: awakening the deafened brain. Nat. Neurosci. 12, 686-691. doi:10.1038/nn.2326

Näätänen, R., Paavilainen, P., Rinne, T., and Alho, K. (2007). The mismatch negativity $(\mathrm{MMN})$ in basic research of central auditory processing: a review. Neurophysiol. Clin. 118, 2544-2590. doi:10.1016/j.clinph.2007.04.026

Näätänen, R., Tervaniemi, M., Sussman, E., Paavilainen, P., and Winkler, I. (2001). Primitive intelligence" in the auditory cortex. Trends Neurosci. 24, 283-288. doi:10.1016/S0166-2236(00)01790-2

North, A. C., Hargreaves, D. J., and O'Neill, S. A. (2000). The importance of music to adolescents. Br. J. Educ. Psychol. 70, 255-272. doi:10.1348/000709900158083

Olszewski, C., Gfeller, K., Froman, R., Stordahl, J., and Tomblin, B. (2005). Familiar melody recognition by children and adults using cochlear implants and normal hearing children. Cochlear. Implants. Int. 6, 123-140. doi:10.1002/cii.5

Overy, K. (2003). Dyslexia and music. From timing deficits to musical intervention. Ann. N. Y. Acad. Sci. 999, 497-505. doi:10.1196/annals.1284.060

Overy, K., Nicolson, R. I., Fawcett, A. J., and Clarke, E. F. (2003). Dyslexia and music: measuring musical timing skills. Dyslexia 9, 18-36. doi:10.1002/dys.233

Pantev, C., Dinnesen, A., Ross, B., Wollbrink, A., and Knief, A. (2006). Dynamics of auditory plasticity after cochlear implantation: a longitudinal study. Cereb. Cortex 16, 31-36. doi:10.1093/cercor/bhi081

Parbery-Clark, A., Skoe, E., and Kraus, N. (2009). Musical experience limits the degradative effects of background noise on the neural processing of sound. J. Neurosci. 29, 14100-14107. doi:10.1523/JNEUROSCI.3256-09.2009

Paukkunen, A. K. (2011). The effect of measurement error on the test-retest reliability of repeated mismatch negativity measurements. Neurophysiol. Clin. 122, 2195-2202. doi:10.1016/j.clinph.2011.04.004

Pedersen, E. R., and Juhl, P. M. L. (2013). User-operated speech in noise test: Implementation and comparison with a traditional test. Int. J. Audiol. 53, 336-344. doi:10.3109/14992027.2013.860486

Petersen, B., Gjedde, A., Wallentin, M., and Vuust, P. (2013a). Cortical plasticity after cochlear implantation. Neural Plast. 2013:318521. doi:10.1155/2013/318521

Petersen, B., Hansen, M., Derdau, S., Ovesen, T., and Vuust, P. (2013b). Aspects of Music With Cochlear Implants - Music Listening Habits and Appreciation in Danish Cochlear Implant Users. Ballerup: The Danavox Jubilee Foundation. Presented at ISAAR, 2013.

Petersen, B., Hansen, R. H., Beyer, K., Mortensen, M. V., and Vuust, P. (2011). Music for little digital ears - music training with preschool children using cochlear implants. Int. J. Pediatr. Otorhinolaryngol. 75, 66. doi:10.1016/S0165-5876(11) 70339-1

Petersen, B., Mortensen, M. V., Hansen, M., and Vuust, P. (2012). Singing in the key of life: a study on effects of musical ear training after cochlear implantation. Psychomusicology 22, 134-151. doi:10.1111/j.1749-6632.2009.04796.x

Pressnitzer, D., Bestel, J., and Fraysse, B. (2005). Music to electric ears: pitch and timbre perception by cochlear implant patients. Ann. N. Y. Acad. Sci. 1060, 343-345. doi:10.1196/annals. 1360.050

Qin, M. K., and Oxenham, A. J. (2003). Effects of simulated cochlear-implant processing on speech reception in fluctuating maskers. J. Acoust. Soc. Am. 114, 446-454. doi:10.1121/1.1579009

Rosenmeier, S. L., and Møller Hansen, N.-H. (2013). CI-unges trivsel og uddannelse. Survey Report. Copenhagen: Rädgivende Sociologer Aps. [In Danish].

Sandmann, P., Eichele, T., Buechler, M., Debener, S., Jancke, L., Dillier, N., et al. (2009). Evaluation of evoked potentials to dyadic tones after cochlear implantation. Brain 132, 1967-1979. doi:10.1093/brain/awp034

Sandmann, P., Kegel, A., Eichele, T., Dillier, N., Lai, W., Bendixen, A., et al. (2010). Neurophysiological evidence of impaired musical sound perception in cochlear-implant users. Neurophysiol. Clin. 121, 2070-2082. doi:10.1016/j. clinph.2010.04.032

Sandmann, P., Plotz, K., Hauthal, N., De Vos, M., Schönfeld, R., and Debener, S. (2014). Rapid bilateral improvement in auditory cortex activity in postlingually deafened adults following cochlear implantation. Clin. Neurophysiol. doi:10.1016/j.clinph.2014.06.029

Sharma, A. (2006). Central auditory development in children with cochlear implants: clinical implications. Adv. Otorhinolaryngol. 64, 66-88.

Sharma, A., Dorman, M. F., and Kral,A. (2005). The influence of a sensitive period on central auditory development in children with unilateral and bilateral cochlear implants. Hear. Res. 203, 134-143. doi:10.1016/j.heares.2004.12.010

Sharma, A., Dorman, M. F., and Spahr, A. J. (2002a). Rapid development of cortical auditory evoked potentials after early cochlear implantation. Neuroreport 13, 1365-1368. doi:10.1097/00001756-200207190-00030
Sharma, A., Dorman, M. F., and Spahr, A. J. (2002b). A sensitive period for the development of the central auditory system in children with cochlear implants: implications for age of implantation. Ear Hear. 23, 532-539. doi:10.1097/00003446200212000-00004

Spitzer, J. B., Mancuso, D., and Cheng, M. Y. (2008). Development of a clinical test of musical perception: appreciation of music in cochlear implantees (AMICI). J. Am. Acad. Audiol. 19, 56-81. doi:10.3766/jaaa.19.1.6

Timm, L., Agrawal, D., Viola, C., Sandmann, P., Debener, S., Buchner, A., et al. (2012). Temporal feature perception in cochlear implant users. PLoS ONE 7:e45375. doi:10.1371/journal.pone.0045375

Timm, L., Vuust, P., Brattico, E., Agrawal, D., Debener, S., Büchner, A., et al. (2014). Residual neural processing of musical sound features in adult cochlear implant users. Front. Hum. Neurosci. 8:181. doi:10.3389/fnhum.2014.00181

Torppa, R., Huotilainen, M., Leminen, M., Lipsanen, J., and Tervaniemi, M. (2014). Interplay between singing and cortical processing of music: a longitudinal study in children with cochlear implants. Front. Psychol. 5:1389. doi:10.3389/fpsyg.2014.01389

Torppa, R., Salo, E., Makkonen, T., Loimo, H., Pykäläinen, J., Lipsanen, J., et al. (2012). Cortical processing of musical sounds in children with cochlear implants. Neurophysiol. Clin. 123, 1966-1979. doi:10.1016/j.clinph.2012.03.008

Veekmans, K., Ressel, L., Mueller, J., Vischer, M., and Brockmeier, S. J. (2009). Comparison of music perception in bilateral and unilateral cochlear implant users and normal-hearing subjects. Audiol. Neurotol. 14, 315-326. doi:10.1159/ 000212111

Viola, F. C., Thorne, J., Edmonds, B., Schneider, T., Eichele, T., and Debener, S. (2009). Semi-automatic identification of independent components representing EEG artifact. Clin. Neurophysiol. 120, 868-877. doi:10.1016/j.clinph.2009.01.015

Viola, F. C., Thorne, J. D., Bleeck, S., Eyles, J., and Debener, S. (2011). Uncovering auditory evoked potentials from cochlear implant users with independent component analysis. Psychophysiology 48, 1470-1480. doi:10.1111/j.1469-8986.2011. 01224.x

Vongphoe, M., and Zeng, F. G. (2005). Speaker recognition with temporal cues in acoustic and electric hearing. J Acoust. Soc. Am. 118, 1055-1061. doi:10.1121/1. 1944507

Vuust, P., Brattico, E., Glerean, E., Seppanen, M., Pakarinen, S., Tervaniemi, M., et al. (2011). New fast mismatch negativity paradigm for determining the neural prerequisites for musical ability. Cortex 47, 1091-1098. doi:10.1016/j.cortex.2011. 04.026

Wagener, K. F., Josvassen, J. L. F. A. U., Ardenkjaer, R., and Ardenkjaer, R. (2003). Design, optimization and evaluation of a Danish sentence test in noise. Int. J. Audiol. 42, 10-17. doi:10.3109/14992020309056080

Won, J. H., Drennan, W. R., Kang, R. S., and Rubinstein, J. T. (2010). Psychoacoustic abilities associated with music perception in cochlear implant users. Ear Hear. 31, 796-805. doi:10.1097/AUD.0b013e3181e8b7bd

Wright, R., and Uchanski, R. M. (2012). Music perception and appraisal: cochlear implant users and simulated cochlear implant listening. J. Am. Acad. Audiol. 23, 350-365. doi:10.3766/jaaa.23.5.6

Zhang, F. (2011). Mismatch negativity and adaptation measures of the late auditory evoked potential in cochlear implant users. Hear. Res. 275, 17-29. doi:10.1016/j.heares.2010.11.007

Conflict of Interest Statement: The authors declare that the research was conducted in the absence of any commercial or financial relationships that could be construed as a potential conflict of interest. The Guest Associate Editor Teppo Särkämö declares that, despite being affiliated to the same institution as author Elvira Brattico, the review process was handled objectively and no conflict of interest exists.

Received: 20 April 2014; accepted: 07 January 2015; published online: 06 February 2015 .

Citation: Petersen B, Weed E, Sandmann P, Brattico E, Hansen M, Sørensen SD and Vuust $P(2015)$ Brain responses to musical feature changes in adolescent cochlear implant users. Front. Hum. Neurosci. 9:7. doi: 10.3389/fnhum.2015.00007 This article was submitted to the journal Frontiers in Human Neuroscience. Copyright (c) 2015 Petersen, Weed, Sandmann, Brattico, Hansen, Sørensen and Vuust. This is an open-access article distributed under the terms of the Creative Commons Attribution License (CC BY). The use, distribution or reproduction in other forums is permitted, provided the original author(s) or licensor are credited and that the original publication in this journal is cited, in accordance with accepted academic practice. No use, distribution or reproduction is permitted which does not comply with these terms. 